\title{
Impacts of Tropical North Atlantic SST on Western North Pacific Landfalling Tropical Cyclones
}

\author{
Si GAO AND ZHIFAN CHEN \\ Key Laboratory of Meteorological Disaster of Ministry of Education, and Joint International Research Laboratory on \\ Climate and Environment Change, and Collaborative Innovation Center on Forecast and Evaluation of \\ Meteorological Disasters, Nanjing University of Information Science and Technology, Nanjing, China
}

\author{
WEI ZHANG
}

IIHR-Hydroscience and Engineering, The University of Iowa, Iowa City, Iowa

(Manuscript received 17 May 2017, in final form 16 October 2017)

\begin{abstract}
This study examines the impacts of tropical North Atlantic (TNA) sea surface temperature anomaly (SSTA) on western North Pacific (WNP) landfalling tropical cyclones (TCs). The authors find that TNA SSTA has significant negative correlations with the frequency of TCs making landfall in China, Vietnam, the Korean Peninsula and Japan, and the entirety of East Asia. TNA SSTA influences the frequency of TC landfalls in these regions by regulating TC genesis location and frequency associated with modulated environmental conditions. During cold TNA SST years, larger low-level relative vorticity and weaker vertical wind shear lead to more TC formations over the South China Sea (SCS) and western Philippine Sea (WPS), and larger low-level relative vorticity, higher midlevel relative humidity, and weaker vertical wind shear result in more TC formations over the eastern part of WNP (EWNP). More TCs forming over different regions are important for more TC landfalls in Vietnam (mainly forming over the SCS and WPS), south China (predominantly forming over the SCS), Taiwan (mostly forming over the WPS), and the Korean Peninsula and Japan (forming over the WPS and EWNP). Tracks of these landfalling TCs basically follow the mean steering flow in spite of different directions of steering flow anomalies in the vicinity. The modulation of large-scale environments by TNA SSTA may be through two possible pathways proposed in previous studies: the Indian Ocean relaying effect and the subtropical eastern Pacific relaying effect. The results of this study suggest that TNA SSTA is a potential predictor for the frequency of TCs making landfall in China, Vietnam, the Korean Peninsula and Japan, and the entirety of East Asia.
\end{abstract}

\section{Introduction}

The western North Pacific (WNP) is a hotbed for tropical cyclones (TCs) that are among the most devastating natural disasters, with a fraction of TCs making landfall and causing significant casualties and economic losses. East Asia accommodates $\sim 25 \%$ of the world's total population, with a large portion dwelling in coastal regions. South China, as a heavily populated coastal area in East Asia, is severely subject to TC-related hazards (Goh and Chan 2010). Understanding environmental conditions responsible for TC landfalls in East Asia is, therefore, of great socioeconomic significance.

TC genesis frequency and location over the WNP have received considerable attention (e.g., Liu and Chan

Corresponding author: Wei Zhang,wei-zhang-3@uiowa.edu
2003; Wu et al. 2005; Zhang et al. 2016a,b). The El NiñoSouthern Oscillation (ENSO) is a well-known coupled atmosphere-ocean phenomenon regulating WNP TC genesis location, although the frequency of TC genesis has no significant linear relationship with ENSO (Lander 1994; Chia and Ropelewski 2002). TCs tend to form in the southeast (northwest) quadrant of the WNP during strong El Niño (La Niña) summers due to favorable environmental conditions (Lander 1994; Chan 2000; Chia and Ropelewski 2002; Wang and Chan 2002; Zhao et al. 2010; Zhan et al. 2011; Liu et al. 2016). Two types of ENSO events exert different impacts on TC genesis positions (Zhang et al. 2012; Wang et al. 2013; Li and Wang 2014; Wang et al. 2014). In addition, WNP TC genesis frequency has been found to be modulated by several factors: the Indian Ocean sea surface temperature (SST) anomaly, the SST gradient between the 
southwest Pacific and western Pacific warm pool, the North Pacific Gyre Oscillation, the Pacific meridional mode, the Atlantic meridional mode, and the North Atlantic Oscillation (Zhan et al. 2011, 2013; Zhou and Cui 2014; Yu et al. 2016a; Zhang et al. 2013, 2016a,b, 2017). Recently, a couple of studies have claimed the contribution of tropical North Atlantic (TNA) SST to WNP TC frequency (Huo et al. 2015; Cao et al. 2016; Yu et al. 2016a,b; Zhang et al. 2017).

Major advancements have been achieved toward understanding the physical mechanisms underlying TC landfalls. Previous studies have found that genesis location and steering flow are two main factors determining TC landfalls (Liu and Chan 2003; Wu et al. 2005; Goh and Chan 2010; Zhang et al. 2012; Zhao 2016). ENSO has strong impacts on TC landfalls in East Asia. More TCs make landfall in China in the late season of La Niña years due to the westward movement of genesis location and enhancement of easterly steering flow (Liu and Chan 2003; Wu et al. 2004, 2005). Different flavors of ENSO show different landfall patterns. There are more landfalling TCs in East Asia (especially the Korean Peninsula and Japan) in the summers of central Pacific El Niño years and fewer (more) landfalling TCs in East Asia during the autumns of eastern Pacific El Niño (La Niña) years, except for in the Korean Peninsula ("Korea" hereafter) and Japan, due to different large-scale environmental conditions (Zhang et al. 2012; Li and Wang 2014).

Although the effects of TNA SST on WNP TC genesis have been well documented using observations and climate model simulations (Huo et al. 2015; Cao et al. 2016; Yu et al. 2016a,b; Zhang et al. 2017), the role of TNA SST in TC landfalls in East Asia is still unclear. Therefore, the objectives of this study are to examine the impacts of TNA SST on the western North Pacific landfalling TCs and to disentangle possible mechanisms underlying such impacts.

\section{Data and methods}

We obtain the frequency of TCs making landfall in East Asia during the peak season [June-October (JJASO)] from the best-track data released by the Regional Specialized Meteorological Center TokyoTyphoon Center (RSMC Tokyo). Only TCs of at least tropical-storm strength [maximum sustained winds exceeding $\left.35 \mathrm{kt}\left(1 \mathrm{kt}=0.51 \mathrm{~m} \mathrm{~s}^{-1}\right)\right]$ were included in this study. The study period is from 1977 to 2016; RSMC Tokyo provides estimates of TC maximum wind speed (MWS) after 1977 because there has been more complete satellite coverage since then. TC track density and genesis density are binned into $2.5^{\circ} \times 2.5^{\circ}$ grid boxes, and a five-point smoothing is used to reduce the noise.
Genesis locations refer to the position where a TC first attains the intensity level of a tropical storm (i.e., MWS $\geq 35 \mathrm{kt}$ ) during its lifespan (Zhang et al. 2012; Gao et al. 2017).

Based on the 1:4000000-scale geological map obtained from the National Geomatics Center of China, East Asia is separated into four subregions: China, Korea and Japan, Vietnam, and the Philippines. China contains mainland China and Taiwan in this study. South China is further defined as Guangdong, Guangxi, and Hainan Provinces. We begin count once a landfalling TC's center moves across the coastline in a subregion. The landfalls after extratropical transition are excluded. It is noted that the frequency of landfalling TCs in the entirety of East Asia is not necessarily equal to the sum of those in the four subregions. A TC that made landfall in the Philippines (one landfall count in the Philippines), and then made landfall in China (one landfall count in China), was counted only once for TCs making landfall in East Asia. Similarly, only one landfall was counted in Korea and Japan for a TC that made landfall in Korea and then made landfall in Japan, and only one landfall was counted in south China and China if a TC made landfall on Taiwan and then made landfall in south China. Landfalling TC frequency in China, derived from our algorithm based on best-track data of both the RSMC Tokyo and the China Meteorological Administration (CMA), is compared with annual TC reports of the CMA in the appendix. The results indicate that data issues, such as insufficient temporal resolution and different estimates of TC intensity and position, cause the differences in the number of TC landfalls. Thus, our algorithm is demonstrated to be reliable.

Monthly mean SST data are acquired from the Extended Reconstructed Sea Surface Temperature (ERSST) version 4 dataset at a spatial resolution of $2^{\circ}$ (Huang et al. 2015). JJASO mean TNA SST of each year is calculated in the area $\left(0^{\circ}-15^{\circ} \mathrm{N}, 90^{\circ} \mathrm{W}-10^{\circ} \mathrm{E}\right)$, consistent with the use of area $\left(0^{\circ}-15^{\circ} \mathrm{N}, 90^{\circ} \mathrm{W}-20^{\circ} \mathrm{E}\right)$ by Ham et al. (2013), because the eastern boundary of TNA is around $10^{\circ} \mathrm{E}$. Another study used slightly different regions (e.g., Huo et al. 2015; Cao et al. 2016; Yu et al. 2016b). The reason for this area selection is that TNA SST in this area has the highest correlation with landfalling TC frequency in almost all the subregions. Because TNA SST is partly influenced by ENSO (e.g., Alexander and Scott 2002; Chiang and Sobel 2002), the ENSO effect is removed by using linear regression onto the Niño-3.4 index in the previous December-February, in accordance with Ham et al. (2013) and Huo et al. (2015). The trend in TNA SST is also removed, as in $\mathrm{Yu}$ et al. (2016b). Normalized time series of the raw TNA SST anomaly (SSTA) and detrended TNA SSTA with 


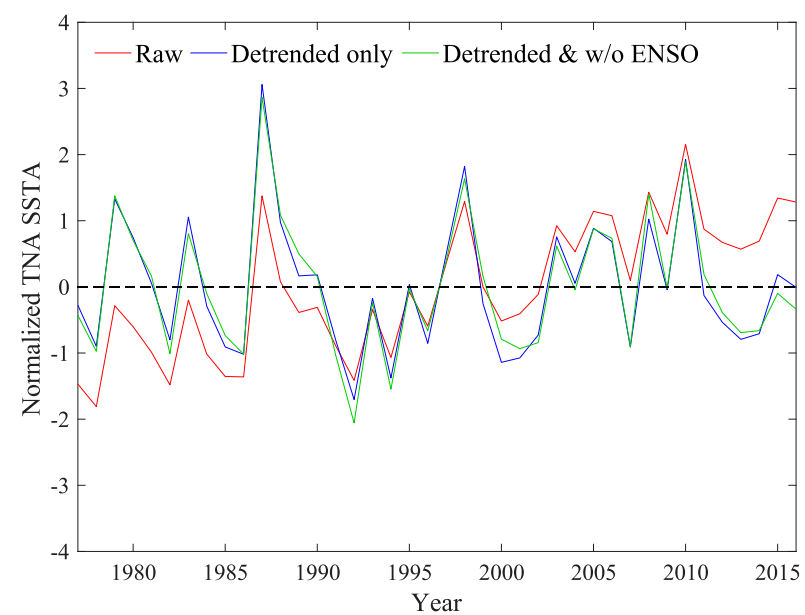

FIG. 1. Normalized time series of raw TNA SSTA (red) and detrended TNA SSTA with and without ENSO (blue and green, respectively) during JJASO 1977-2016.

and without ENSO are shown in Fig. 1. Normalized time series of detrended TNA SSTA with and without ENSO are nearly identical, and the use of them gives very similar results regarding correlations, composites, and regressions. We only present the results using detrended TNA SSTA without ENSO to examine the sole effect of TNA SSTA on WNP TC landfalls. Eight high TNA SST years $(1979,1983,1987,1988,1998,2005,2008$, and 2010) and eight low TNA SST years $(1978,1982,1986$, 1991, 1992, 1994, 2001, and 2007) are selected based on the thresholds of \pm 0.9 standard deviation.

JJASO mean environmental variables, such as wind vector, humidity, temperature, and sea level pressure, are obtained from the National Centers for Environmental Prediction (NCEP)-National Center for Atmospheric Research (NCAR) reanalysis data with a spatial resolution of $2.5^{\circ}$ (Kalnay et al. 1996). Layer-mean wind fields of $850-300 \mathrm{hPa}$ are used to represent steering flow (Chan and Gray 1982; Harr and Elsberry 1991; Velden and Leslie 1991; Chan 2005).

Genesis potential index (GPI; Emanuel and Nolan 2004) is used to diagnose the potential of TC genesis and is defined as

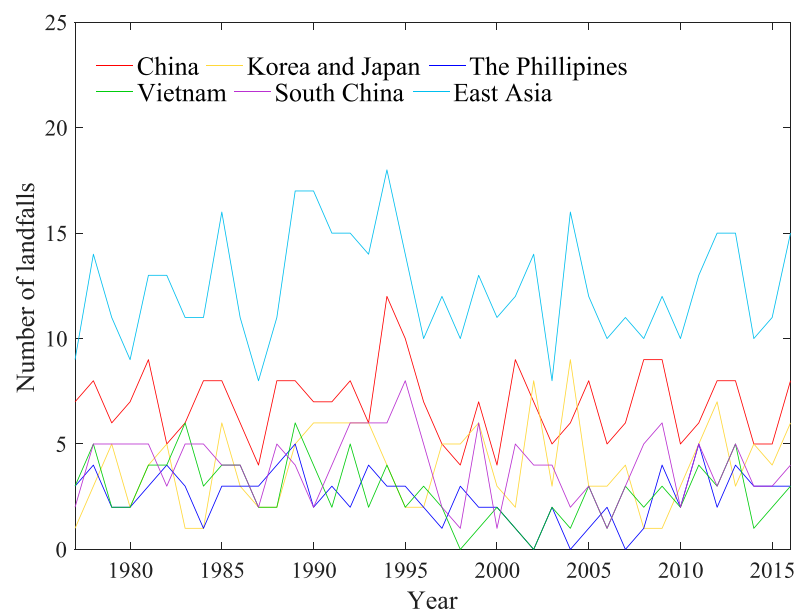

FIG. 2. Time series of the frequency of TCs making landfall in China (red), Korea and Japan (orange), the Philippines (dark blue), Vietnam (green), south China (purple), and the entire East Asian coast (light blue) during JJASO 1977-2016.

GPI $=\left|10^{5} \eta\right|^{3 / 2}\left(\frac{H}{50}\right)^{3}\left(\frac{V_{\text {pot }}}{70}\right)^{3}\left(1+0.1 V_{\text {shear }}\right)^{-2}$

where $\eta$ is the $850-\mathrm{hPa}$ absolute vorticity $\left(\mathrm{s}^{-1}\right), H$ is the 600 -hPa relative humidity (\%), $V_{\text {pot }}$ is the maximum potential intensity (MPI; $\mathrm{m} \mathrm{s}^{-1}$ ) defined by (Emanuel $1988)$, and $V_{\text {shear }}$ is the magnitude of vertical wind shear from 850 to $200 \mathrm{hPa}\left(\mathrm{m} \mathrm{s}^{-1}\right)$. GPI has been widely used to assess the potential of TC genesis associated with ENSO or TNA SSTA in previous studies (e.g., Camargo et al. 2007; Yu et al. 2016b).

\section{Results}

The frequency of TCs making landfall in different subregions and the entire East Asian coast are shown in Fig. 2. Within a 40-yr average, there are 7.0, 4.0, 4.0, 2.5, 2.8, and 12.4 TCs making landfall in China, south China, Korea and Japan, the Philippines, Vietnam, and the entirety of East Asia, respectively (Table 1). The mean differences in landfalling TCs in these regions between

TABLE 1. Mean and standard deviation (shown in parentheses) of landfalling TC frequency during JJASO 1977-2016, high and low TNA SST years, and difference between the means of low and high TNA SST years for each region.

\begin{tabular}{|c|c|c|c|c|c|c|}
\hline Region & China & South China & Korea and Japan & The Philippines & Vietnam & East Asia \\
\hline 1977-2016 & $7.0(1.8)$ & $4.0(1.6)$ & $4.0(2.0)$ & $2.5(1.3)$ & $2.8(1.5)$ & $12.4(2.6)$ \\
\hline High TNA SST years & $6.3(1.9)$ & $3.5(1.7)$ & $2.8(1.6)$ & $2.4(1.1)$ & $2.4(1.7)$ & $10.4(1.2)$ \\
\hline Low TNA SST years & $7.6(2.2)$ & $4.5(1.2)$ & $4.1(1.5)$ & $2.5(1.4)$ & $3.5(1.4)$ & $13.6(2.4)$ \\
\hline Low-high TNA SST years & $1.3^{\mathrm{a}}$ & $1.0^{\mathrm{a}}$ & $1.3^{\mathrm{b}}$ & 0.1 & $1.1^{\mathrm{a}}$ & $3.2^{\mathrm{c}}$ \\
\hline
\end{tabular}

\footnotetext{
a $80 \%$ confidence level.

b $90 \%$ confidence level.

c 99\% confidence level.
} 
TABLE 2. Correlation coefficients $(r)$ between the detrended TNA SSTA with and without ENSO signal and landfalling TC frequency over each subregion and the entirety of East Asia.

\begin{tabular}{lcccccc}
\hline \hline \multicolumn{1}{c}{ Region } & China & South China & Korea and Japan & The Philippines & Vietnam & East Asia \\
\hline$r$ (w/o ENSO) & $-0.36^{\mathrm{b}}$ & $-0.27^{\mathrm{a}}$ & $-0.28^{\mathrm{a}}$ & -0.00 & $-0.28^{\mathrm{a}}$ & $-0.51^{\mathrm{c}}$ \\
$r$ (w/ ENSO) & $-0.38^{\mathrm{b}}$ & $-0.30^{\mathrm{a}}$ & -0.25 & -0.00 & $-0.28^{\mathrm{a}}$ & $-0.51^{\mathrm{c}}$ \\
\hline
\end{tabular}

a significance at the 0.1 level.

${ }^{\mathrm{b}}$ significance at the 0.05 level.

${ }^{\mathrm{c}}$ significance at the 0.01 level.

selected low and high TNA SST years are 1.3, 1.0, 1.3, $0.1,1.1$, and 3.2, respectively (Table 1). All the differences are significant at $80 \%$ confidence level or above, except for those of the Philippines. Although the confidence levels of the differences in China, south China, and Vietnam are only $80 \%$ (Table 1 ), the counts of landfalling TCs in all the subregions and the entirety of East Asia, except for the Philippines, show significant negative correlations with the detrended TNA SSTA at the confidence level of $90 \%$ or higher (Table 2). Because of the negative signs of significant correlations, a TNA index (TNAI) is defined by multiplying -1 to the normalized TNA SSTA without trend and ENSO to assess how TNA SSTA affects the frequency of TCs making landfall in those regions.

Figure 3 indicates regression patterns of JJASO TC track density and genesis density, steering flow, and GPI on the TNAI. Based on the regression pattern of genesis density in Fig. 3b, four subregions are divided: the South China Sea (SCS; $\left.5^{\circ}-25^{\circ} \mathrm{N}, 105^{\circ}-122^{\circ} \mathrm{E}\right)$, the western Philippine Sea (WPS; $5^{\circ}-25^{\circ} \mathrm{N}, 122^{\circ}-132^{\circ} \mathrm{E}$ ), the eastern
Philippine Sea (EPS; $5^{\circ}-25^{\circ} \mathrm{N}, 132^{\circ}-142^{\circ} \mathrm{E}$ ), and the eastern part of WNP (EWNP; $\left.5^{\circ}-25^{\circ} \mathrm{N}, 142^{\circ}-180^{\circ} \mathrm{E}\right)$. During low TNA SST years, there is significantly high TC activity along the coast of north Vietnam, south China, Taiwan, Korea, and south Japan (Fig. 3a), which is largely associated with more TC formations over the SCS, WPS, and EWNP (Fig. 3b). A thorough comparison of landfalling TC tracks and the associated composite steering flow (Figs. 4, 5) shows the following during low TNA SST years (Figs. 4b, 5b): 1) more TCs mainly forming over the SCS and WPS travel westward or northwestward and make landfall in Vietnam (Fig. 4b), 2) more TCs mainly forming over the SCS travel northwestward or northward and make landfall in south China (Fig. 4b), 3) more TCs mainly forming over the WPS travel northwestward and make landfall on Taiwan (Fig. 4b; landfalling TC frequency on Taiwan has a significant correlation of 0.28 with the TNAI), and 4) more TCs forming over the WPS and EWNP take regular northeastward recurving paths and make landfall in Korea and Japan (Fig. 5b). All the landfalling TCs
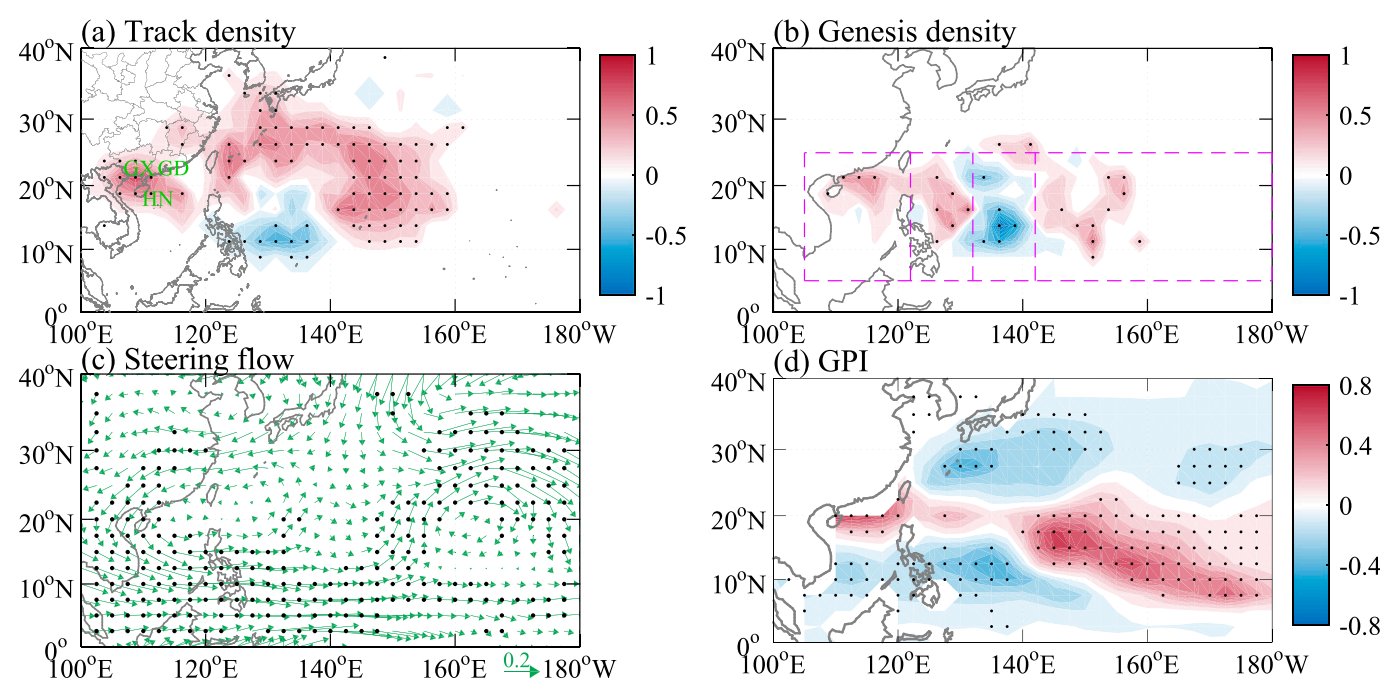

FIG. 3. Regressions of JJASO (a) track density, (b) genesis density, (c) steering flow ( $\mathrm{m} \mathrm{s}^{-1}$ ), and (d) GPI anomalies on the TNAI. GD, GX, and HN in (a) refer to Guangdong, Guangxi, and Hainan Provinces of China. Regression coefficients exceeding $90 \%$ confidence level are stippled. Four purple rectangles from left to right in (b) represent the subregions of SCS, WPS, EPS, and EWNP. 
(a) Tracks (high TNA SST)

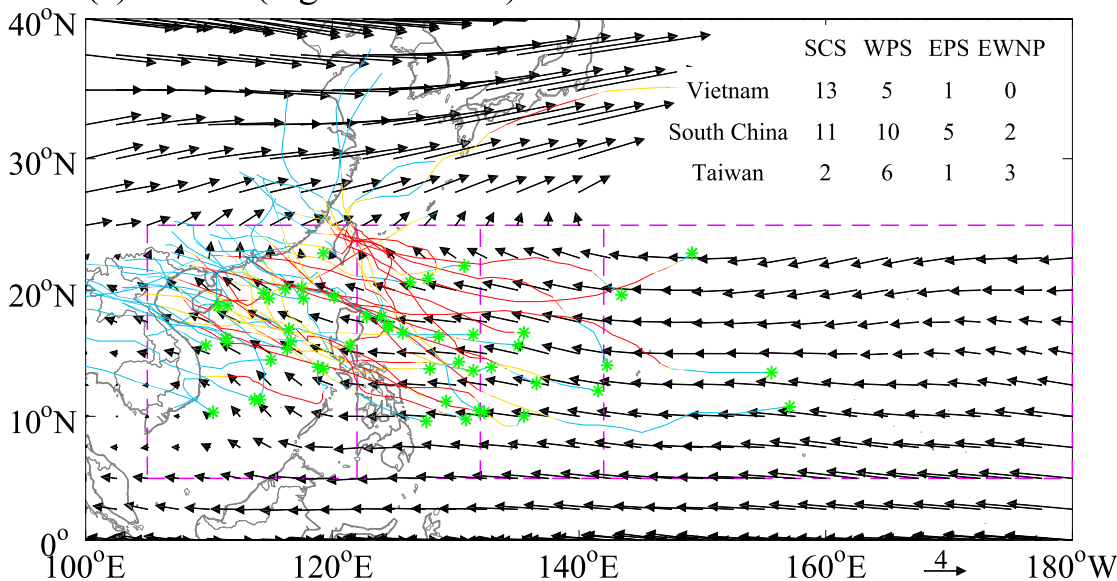

(b) Tracks (low TNA SST)

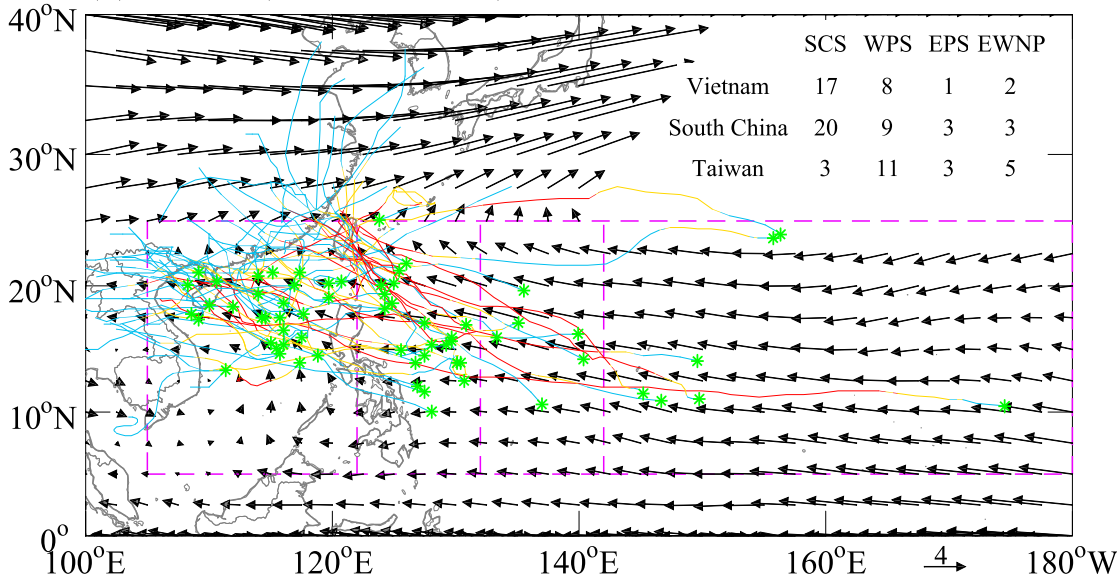

FIG. 4. Tracks of TCs making landfall in Vietnam, south China, and Taiwan (curves) and composite steering flow (vectors, $\mathrm{m} \mathrm{s}^{-1}$ ) during JJASO of selected (a) high and (b) low TNA SST years. Green asterisks denote the locations of TC genesis. Orange and red tracks represent the intensity level of severe storms $(48-63 \mathrm{kt})$ and typhoons $(\geq 64 \mathrm{kt})$, respectively. Blue tracks represent the intensity levels of both tropical depression $(<35 \mathrm{kt})$ in the dissipation stage and tropical storms (35-47 kt). Purple rectangles have the same meanings as in Fig. 3b. Numbers of landfalling TCs forming over different regions are shown in the upper right of each panel.

basically follow the composite steering flow (Figs. 4b, $5 b)$ in spite of different directions of significant or insignificant steering flow anomalies in the vicinity (Fig. 3c). The difference in the composite steering flow between low and high TNA SST years (Fig. 6) further confirms that the steering flow anomalies do not play a dominant role in landfalling TC tracks in high and low TNA SST years. The results suggest that the impacts of TNA SSTA on genesis frequency and location play crucial roles in the regulation of TC landfalls in East Asia; however, the impact of TNA SSTA on steering flow appears to play a minor role because the induced steering flow anomalies (Fig. 6) are not large enough to change the steering flow direction (Figs. 4, 5).
The differences in GPI (Fig. 3d) are generally in good agreement with those in genesis density (Fig. 3b) except for a discrepancy between GPI and genesis density over the WPS (Fig. 3b vs Fig. 3d). Similar to Yu et al. (2016b), four parameters of GPI-that is, $850-\mathrm{hPa}$ absolute vorticity, 600-hPa relative humidity, maximum potential intensity, and the magnitude of $850-200-\mathrm{hPa}$ vertical wind shearare used to further diagnose TC genesis associated with different TNA SSTA (Fig. 7). During low TNA SST years, more TC formations over the SCS and WPS are favored by larger low-level relative vorticity (Fig. 7a) and weaker vertical wind shear (Fig. 7d). Moreover, larger low-level relative vorticity (Fig. 7a), higher midlevel relative humidity (Fig. 7b), and weaker vertical wind shear (Fig. 7d) are 
(a) Tracks (high TNA SST)

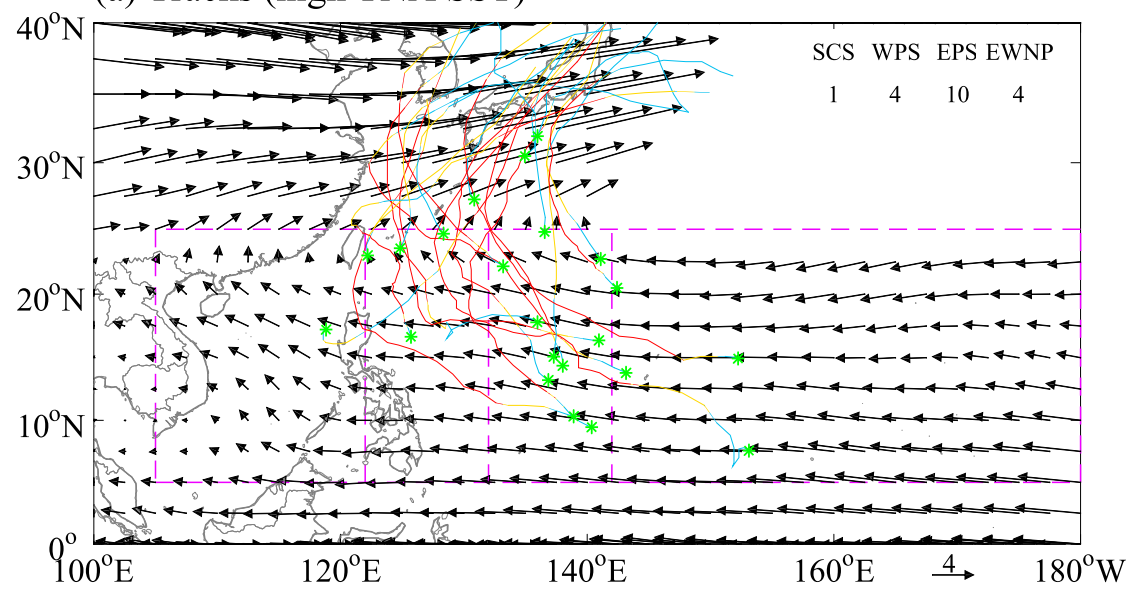

(b) Tracks (low TNA SST)

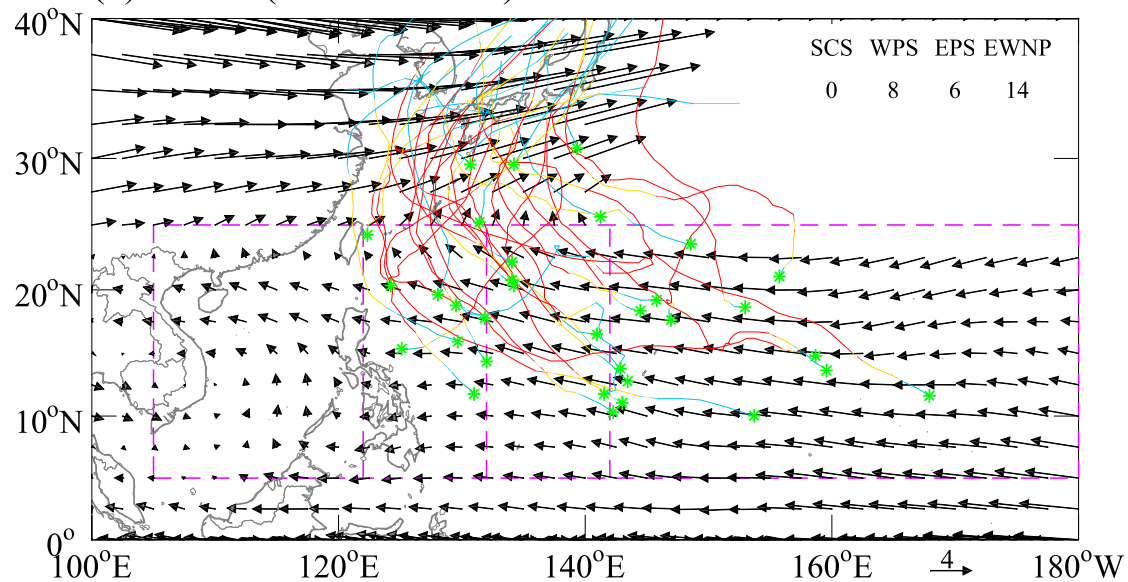

FIG. 5. As in Fig. 4, but for tracks of TCs making landfall in Korea and Japan.

responsible for more TC formations over the EWNP. This is consistent with Zhang et al. (2017), in which the SSTA in the North Atlantic strongly modulates WNP TC genesis by changing vertical wind shear over the WNP. Negative regression coefficients of GPI over the WPS (Fig. 3d), which are opposite to positive regression coefficients of TC genesis density anomalies over the same area (Fig. 3b), are mainly attributed to a few factors: the significantly stronger vertical wind shear (Fig. 7d) during low TNA SST years, the unfavorable (though insignificant) midlevel relative humidity (Fig. 7b), and the MPI (Fig. 7c), which may also play some roles because of the nonlinear calculation of GPI. The regression pattern of MPI (Fig. 7c) is generally inconsistent with that of TC genesis density (Fig. 3b) due primarily to lower SST in the WNP during low TNA SST years (Fig. 8).

\section{Discussion}

Our results suggest that TNA SSTAs regulate the frequency of TCs making landfall in East Asia by influencing
TC genesis frequency and location. As illustrated in Fig. 8, the physical mechanism is largely consistent with two possible pathways for relaying TNA signals to the WNP (Ham et al. 2013) and the Indian Ocean relaying effect on WNP TC genesis (Yu et al. 2016b) using idealized numerical experiments. The first pathway is an eastward relay of TNA signals to the WNP (Ham et al. 2013; Yu et al. 2016b); a cold SSTA in the TNA induces low-level westerly anomalies over the north Indian Ocean (NIO) through Gill-type Kelvin wave propagation (Gill 1980). The westerly anomalies, together with mean summertime westerly flow over the NIO, result in anomalous westerly winds and thus enhance oceanic evaporation and vertical mixing. This cools down SST in the NIO, further inducing low-level westerly anomalies over low latitudes over the SCS and WNP and therefore anomalous cyclonic flow in most of the main development region over the SCS and WNP (Fig. 8).

The second pathway is a westward relay of TNA signal to the WNP (Ham et al. 2013); a cold TNA SSTA 


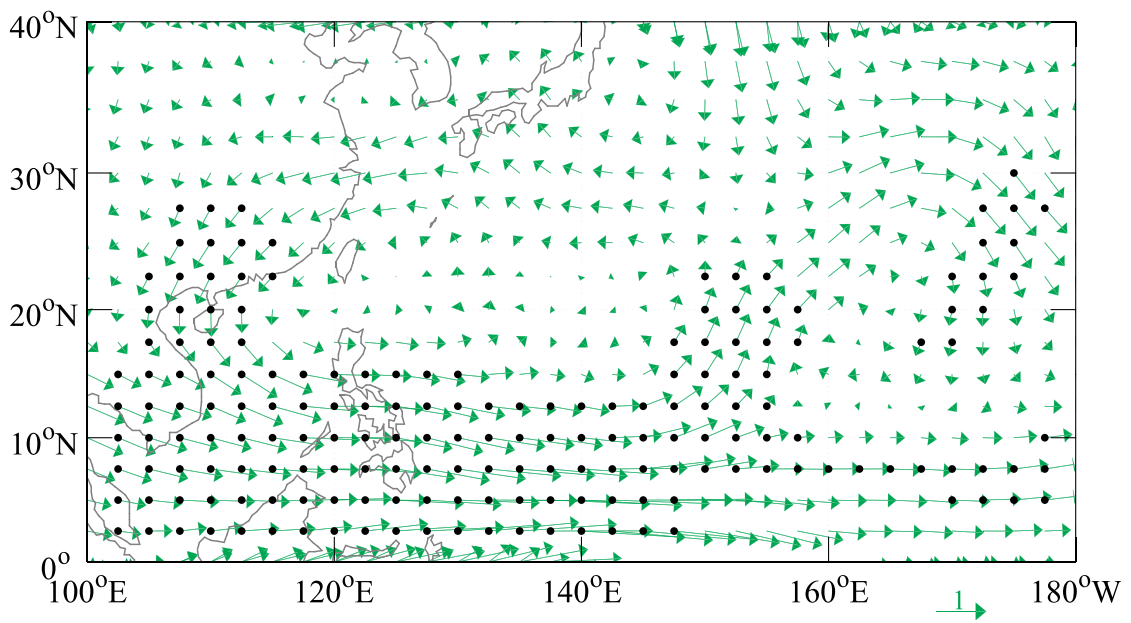

FIG. 6. Difference in the composite steering flow $\left(\mathrm{m} \mathrm{s}^{-1}\right)$ between low and high TNA SST years. (low-high TNA SST years). Values exceeding $90 \%$ confidence level are stippled.

induces easterly anomalies and an anomalous low-level anticyclonic flow over the subtropical eastern Pacific as a Gill-type Rossby wave response (Gill 1980), which generates southerly anomalies on its west flank. The southerly anomalies give rise to surface warming due to weakened wind speed and warm advection from lower latitudes. The warm SSTA and associated enhanced convection produce an anomalous low-level cyclonic flow over the western and central North Pacific (Fig. 8).

Low-level vorticity, midlevel relative humidity, and vertical wind shear responsible for anomalous TC formations are all associated with large-scale environments, modulated by TNA SSTA through the two possible relaying pathways.

(a) $850-\mathrm{hPa}$ relative vorticity
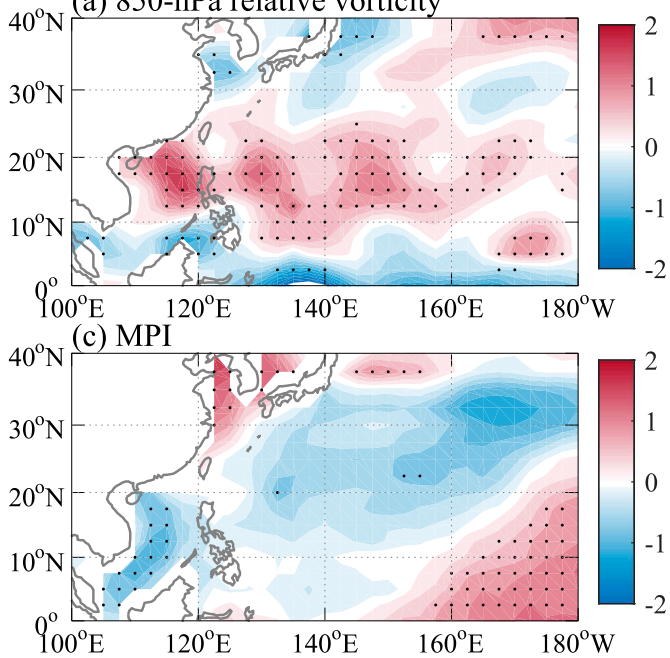

\section{Conclusions}

The impacts of TNA SSTA on landfalling WNP TC frequency in East Asia are examined. Results show that landfalling TC counts in China, south China, Vietnam, Korea and Japan, and the entirety of East Asia have significant negative correlations with TNA SSTA. Further analyses suggest that both genesis frequency and location play important roles in TC landfalls, and largescale environments are responsible for anomalous TC genesis location and frequency. Specifically, during cold TNA SST years, larger low-level relative vorticity and weaker vertical wind shear lead to more TC formations over the SCS and WPS, and larger low-level relative
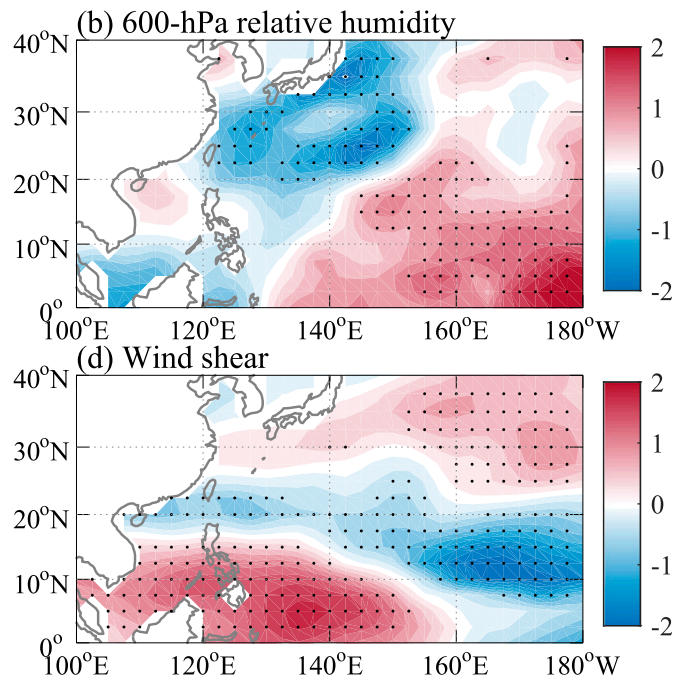

FIG. 7. Regressions of JJASO (a) 850 -hPa relative vorticity $\left(10^{-6} \mathrm{~s}^{-1}\right)$, (b) 600-hPa relative humidity (\%), (c) MPI $\left(\mathrm{m} \mathrm{s}^{-1}\right)$, and (d) vertical wind shear $\left(\mathrm{m} \mathrm{s}^{-1}\right)$ anomalies on the TNAI. Regression coefficients exceeding $90 \%$ confidence level are stippled. 


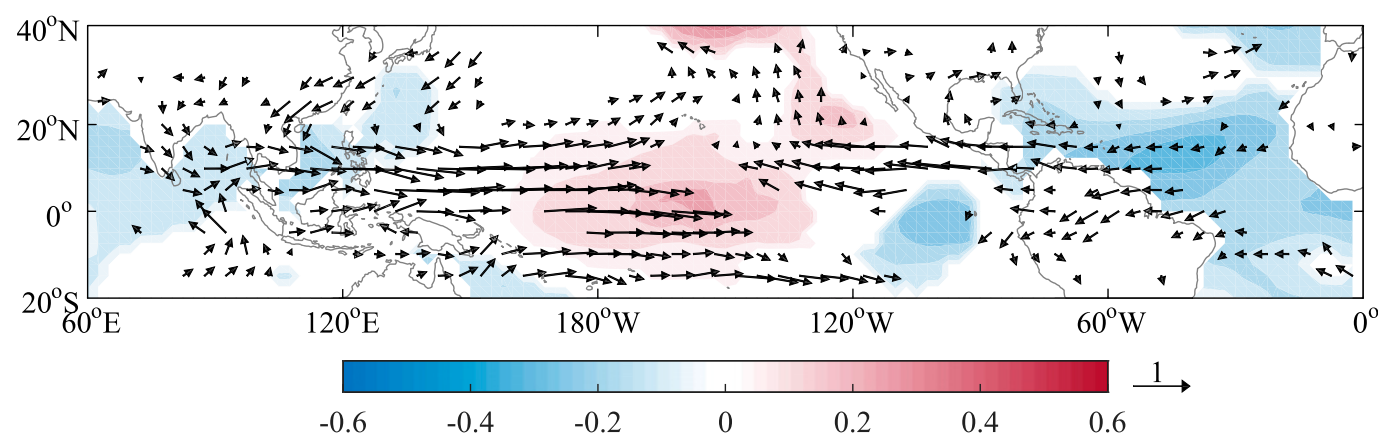

FIG. 8. Regressions of JJASO SST (shaded, ${ }^{\circ} \mathrm{C}$ ) and $850-\mathrm{hPa}$ wind field (vector, $\mathrm{m} \mathrm{s}^{-1}$ ) anomalies on the TNAI.

Only the regression coefficients exceeding $90 \%$ confidence level are shown.

vorticity, higher midlevel relative humidity, and weaker vertical wind shear result in more TC formations over the EWNP. More TC formations over different regions results in more TC landfalls in Vietnam (mainly forming over the SCS and WPS), south China (predominantly forming over the SCS), Taiwan (mostly forming over the WPS), and Korea and Japan (forming over the WPS and EWNP). These TCs travel and make landfall basically in accordance with the mean steering flow, although directions of steering flow anomalies in the vicinity are different. The modulation of large-scale environments by TNA SSTA may be through two possible pathways, that is, the Indian Ocean relaying effect and the subtropical eastern Pacific relaying effect, that are proposed in previous studies (e.g., Ham et al. 2013; Yu et al. 2016b).

In addition to the well-known predictors (i.e., ENSOrelated indices) (Liu and Chan 2003; Wu et al. 2005; Goh and Chan 2010; Zhang et al. 2012; Li and Wang 2014), this study suggests that TNA SSTA is also a potential predictor for the frequency of TCs making landfall in China, Vietnam, Korea and Japan, and the entirety of East Asia.

Acknowledgments. NCEP-NCAR Reanalysis data and NOAA ERSST v4 data are provided by the NOAA/ OAR/ESRL PSD (Boulder, Colorado; http://www.esrl. noaa.gov/psd/). RMSC Tokyo TC best-track data are provided by the Japan Meteorological Agency/RMSC Tokyo-Typhoon Center (http://www.jma.go.jp/jma/jmaeng/jma-center/rsmc-hp-pub-eg/besttrack.html). CMA TC best-track data and annual TC reports are provided by the CMA/Shanghai Typhoon Institute (http://tcdata. typhoon.org.cn/en/). We are grateful to two anonymous reviewers for the helpful comments and suggestions that significantly improved the earlier version of the manuscript. This paper was jointly supported by the National Natural Science Foundation of China (41575078 and 41505035), the Jiangsu Shuangchuang Doctor Program, and the Priority Academic Program Development of Jiangsu Higher Education Institutions (PAPD). This paper is Earth System Modelling Center Contribution Number 192.

\section{APPENDIX}

\section{Comparison of Landfalling TC Frequency in China from the Algorithm and from Annual TC Reports of the CMA}

To validate our algorithm, we conduct a thorough comparison of landfalling TC frequency in China from the algorithm and from annual TC reports of the CMA. Time series of landfalling TC frequency based on the RSMC Tokyo and CMA best-track (Ying et al. 2014) data and from annual TC reports of CMA are shown in Fig. A1. Landfalling TC frequency in China based on the CMA best-track data is consistent with that from annual TC reports of CMA, except for the difference of one landfall in each of these years: 1987, 1989, 2007, 2010, and 2011. The inability of the algorithm to detect those

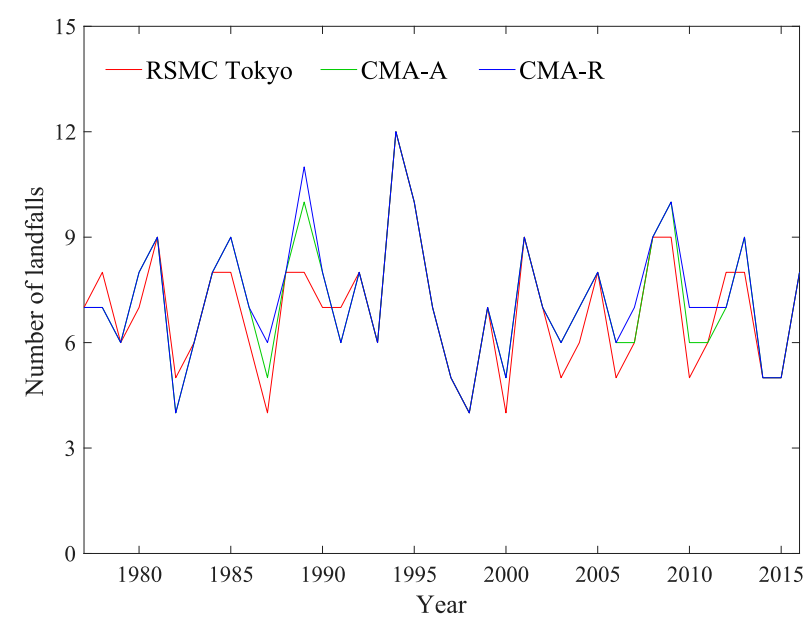

FIG. A1. Time series of landfalling TC frequency in China derived from the algorithm based on the RMSC Tokyo and CMA best-track data (red and green, respectively) and from annual TC reports of CMA (blue). 


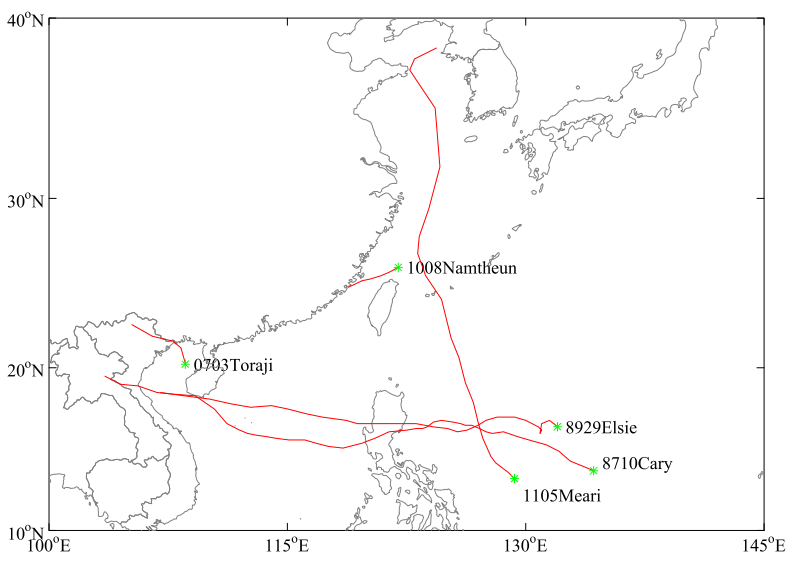

FIG. A2. Six-hourly CMA tracks of the five TCs that made landfall in China according to annual TC reports of the CMA; their landfalls cannot be detected by the algorithm due to insufficient temporal resolution of best-track data.

landfalls is because the five TCs [Cary (1987), Elsie (1989), Toraji (2007), Namtheun (2010), and Meari (2011); see their tracks in Fig. A2] moved along the coast and made landfall some time in between the standard 6-h interval.

Comparisons of landfalling TC frequency based on the RSMC Tokyo and CMA best-track data show differences of one or two landfalls in 18 years. There are two reasons for that. The first reason is the difference in estimating TC intensity between two agencies, that is, a landfalling TC reached tropical-storm strength according to one agency, but it did not according to the other agency; thus, the TC was not recorded. Specifically, the RSMC Tokyo did not record TCs Bess (1978), 8008 (1980), 8503 (1985), 8613 (1986), 8912 (1989), Cecil (1990), 0411 (2004), and a nameless TC in 2009 that made landfall in the CMA besttrack data. The CMA did not record TC Bonnie (1978) that made landfall in the RSMC Tokyo best-track data. The second reason is the difference in estimating TC position between two agencies, especially near the coast. These TCs include Nina (1978), Vall (1982), Vernon (1987), 8918 (1989), Ellie (1991), Wukong (2000), Vamco (2003), Vicente (2005), Jelawat (2006), Conson (2010), Talim (2012), and Cimaron (2013). The results indicate that it is the data issues (i.e., insufficient temporal resolution and different estimates of TC intensity and position) that cause the differences in the detected landfalling $\mathrm{TC}$ frequency. Our algorithm is, therefore, quite reliable.

\section{REFERENCES}

Alexander, M., and J. Scott, 2002: The influence of ENSO on airsea interaction in the Atlantic. Geophys. Res. Lett., 29, 1701, https://doi.org/10.1029/2001GL014347.
Camargo, S. J., K. A. Emanuel, and A. H. Sobel, 2007: Use of a genesis potential index to diagnose ENSO effects on tropical cyclone genesis. J. Climate, 20, 4819-4834, https://doi.org/ 10.1175/JCLI4282.1.

Cao, X., S. Chen, G. Chen, and R. Wu, 2016: Intensified impact of northern tropical Atlantic SST on tropical cyclogenesis frequency over the western North Pacific after the late 1980s. Adv. Atmos. Sci., 33, 919-930, https://doi.org/ 10.1007/s00376-016-5206-z.

Chan, J. C. L., 2000: Tropical cyclone activity over the western North Pacific associated with El Niño and La Niña events. J. Climate, 13, 2960-2972, https://doi.org/10.1175/1520-0442(2000)013<2960: TCAOTW $>2.0 . \mathrm{CO} ; 2$.

- 2005: The physics of tropical cyclone motion. Annu. Rev. Fluid Mech., 37, 99-128, https://doi.org/10.1146/annurev.fluid. 37.061903.175702.

— , and W. M. Gray, 1982: Tropical cyclone movement and surrounding flow relationships. Mon. Wea. Rev., 110, 13541374, https://doi.org/10.1175/1520-0493(1982)110<1354: TCMASF $>2.0 . \mathrm{CO} ; 2$.

Chia, H. H., and C. F. Ropelewski, 2002: The interannual variability in the genesis location of tropical cyclones in the northwest Pacific. J. Climate, 15, 2934-2944, https://doi.org/ 10.1175/1520-0442(2002)015<2934:TIVITG > 2.0.CO;2.

Chiang, J. C., and A. H. Sobel, 2002: Tropical tropospheric temperature variations caused by ENSO and their influence on the remote tropical climate. J. Climate, 15, 26162631, https://doi.org/10.1175/1520-0442(2002)015<2616: TTTVCB $>2.0 . \mathrm{CO} ; 2$.

Emanuel, K. A., 1988: The maximum intensity of hurricanes. J. Atmos. Sci., 45, 1143-1155, https://doi.org/10.1175/ 1520-0469(1988)045<1143:TMIOH >2.0.CO;2.

— climate. 26th Conf. on Hurricanes and Tropical Meteorology, Miami, FL, Amer. Meteor. Soc., 10A.2, https://ams.confex.com/ ams/26HURR/techprogram/paper_75463.htm.

Gao, S., B. Chen, T. Li, N. Wu, and W. Deng, 2017: AIRS-observed warm core structures of tropical cyclones over the western North Pacific. Dyn. Atmos. Oceans, 77, 100-106, https://doi.org/ 10.1016/j.dynatmoce.2016.12.001.

Gill, A. E., 1980: Some simple solutions for heat-induced tropical circulation. Quart. J. Roy. Meteor. Soc., 106, 447-462, https:// doi.org/10.1002/qj.49710644905.

Goh, A. Z.-C., and J. C. L. Chan, 2010: An improved statistical scheme for the prediction of tropical cyclones making landfall in South China. Wea. Forecasting, 25, 587-593, https://doi.org/ 10.1175/2009WAF2222305.1.

Ham, Y.-G., J.-S. Kug, J.-Y. Park, and F.-F. Jin, 2013: Sea surface temperature in the north tropical Atlantic as a trigger for El Niño/Southern Oscillation events. Nat. Geosci., 6, 112-116, https://doi.org/10.1038/ngeo1686.

Harr, P. A., and R. L. Elsberry, 1991: Tropical cyclone track characteristics as a function of large-scale circulation anomalies. Mon. Wea. Rev., 119, 1448-1468, https://doi.org/10.1175/ 1520-0493(1991)119<1448:TCTCAA > 2.0.CO;2.

Huang, B., and Coauthors, 2015: Extended Reconstructed Sea Surface Temperature version 4 (ERSST.v4). Part I: Upgrades and intercomparisons. J. Climate, 28, 911-930, https://doi.org/ 10.1175/JCLI-D-14-00006.1.

Huo, L., P. Guo, S. N. Hameed, and D. Jin, 2015: The role of tropical Atlantic SST anomalies in modulating western North Pacific tropical cyclone genesis. Geophys. Res. Lett., 42, 23782384, https://doi.org/10.1002/2015GL063184. 
Kalnay, E., and Coauthors, 1996: The NCEP/NCAR 40-Year Reanalysis Project. Bull. Amer. Meteor. Soc., 77, 437-471, https:// doi.org/10.1175/1520-0477(1996)077<0437:TNYRP>2.0.CO;2.

Lander, M. A., 1994: An exploratory analysis of the relationship between tropical storm formation in the western North Pacific and ENSO. Mon. Wea. Rev., 122, 636-651, https://doi.org/ 10.1175/1520-0493(1994)122<0636:AEAOTR>2.0.CO;2.

Li, C., and C. Wang, 2014: Simulated impacts of two types of ENSO events on tropical cyclone activity in the western North Pacific: Large-scale atmospheric response. Climate Dyn., 42, 2727-2743, https://doi.org/10.1007/s00382-0131999-y.

Liu, F., T. Li, H. Wang, L. Deng, and Y. Zhang, 2016: Modulation of boreal summer intraseasonal oscillations over the western North Pacific by ENSO. J. Climate, 29, 7189-7201, https://doi.org/10.1175/JCLI-D-15-0831.1.

Liu, K. S., and J. C. L. Chan, 2003: Climatological characteristics and seasonal forecasting of tropical cyclones making landfall along the South China coast. Mon. Wea. Rev., 131, 1650-1662, https://doi.org/10.1175//2554.1.

Velden, C. S., and L. M. Leslie, 1991: The basic relationship between tropical cyclone intensity and the depth of the environmental steering layer in the Australian region. Wea. Forecasting, 6, 244-253, https://doi.org/10.1175/1520-0434(1991)006<0244: TBRBTC $>2.0 . \mathrm{CO} ; 2$.

Wang, B., and J. C. L. Chan, 2002: How strong ENSO events affect tropical storm activity over the western North Pacific. J. Climate, 15, 1643-1658, https://doi.org/10.1175/1520-0442(2002)015<1643: HSEEAT $>2.0 . \mathrm{CO} ; 2$.

Wang, C., C. Li, M. Mu, and W. Duan, 2013: Seasonal modulations of different impacts of two types of ENSO events on tropical cyclone activity in the western North Pacific. Climate Dyn., 40, 2887-2902, https://doi.org/10.1007/s00382-012-1434-9.

Wang, X., W. Zhou, C. Li, and D. Wang, 2014: Comparison of the impact of two types of El Niño on tropical cyclone genesis over the South China Sea. Int. J. Climatol., 34, 2651-2660, https:// doi.org/10.1002/joc. 3865 .

Wu, L., B. Wang, and S. Geng, 2005: Growing typhoon influence on East Asia. Geophys. Res. Lett., 32, L18703, https://doi.org/ 10.1029/2005GL022937.

Wu, M. C., W. L. Chang, and W. M. Leung, 2004: Impacts of El Niño-Southern Oscillation events on tropical cyclone landfalling activity in the western North Pacific. J. Climate, 17, 1419-1428, https://doi.org/10.1175/1520-0442(2004)017<1419: IOENOE $>2.0 . \mathrm{CO} ; 2$.

Ying, M., W. Zhang, H. Yu, X. Lu, J. Feng, Y. Fan, Y. Zhu, and D. Chen, 2014: An overview of the China Meteorological Administration tropical cyclone database. J. Atmos. Oceanic Technol., 31, 287-301, https://doi.org/10.1175/JTECH-D-12-00119.1.

Yu, J., C. Chen, T. Li, X. Zhao, H. Xue, and Q. Sun, 2016a: Contribution of major SSTA modes to the climate variability of tropical cyclone genesis frequency over the western North Pacific. Quart. J. Roy. Meteor. Soc., 142, 1171-1181, https:// doi.org/10.1002/qj.2722.

— T. Li, Z. Tan, and Z. Zhu, 2016b: Effects of tropical North Atlantic SST on tropical cyclone genesis in the western North Pacific. Climate Dyn., 46, 865-877, https://doi.org/10.1007/ s00382-015-2618-x.

Zhan, R., Y. Wang, and X. Lei, 2011: Contributions of ENSO and east Indian Ocean SSTA to the interannual variability of northwest Pacific tropical cyclone frequency. J. Climate, 24, 509-521, https://doi.org/10.1175/2010JCLI3808.1.

— — - and M. Wen, 2013: The SST gradient between the southwest Pacific and the western Pacific warm pool: A new factor controlling the northwestern Pacific tropical cyclone genesis frequency. J. Climate, 26, 2408-2415, https://doi.org/ 10.1175/JCLI-D-12-00798.1.

Zhang, W., H.-F. Graf, Y. Leung, and M. Herzog, 2012: Different El Niño types and tropical cyclone landfall in East Asia. J. Climate, 25, 6510-6523, https://doi.org/10.1175/ JCLI-D-11-00488.1.

_, Y. Leung, and J. Min, 2013: North Pacific Gyre Oscillation and the occurrence of western North Pacific tropical cyclones. Geophys. Res. Lett., 40, 5205-5211, https://doi.org/ 10.1002/grl.50955.

—, G. A. Vecchi, H. Murakami, G. Villarini, and L. Jia, 2016a: The Pacific meridional mode and the occurrence of tropical cyclones in the western North Pacific. J. Climate, 29, 381-398, https://doi.org/10.1175/JCLI-D-15-0282.1.

_ , and Coauthors, 2016b: Improved simulation of tropical cyclone responses to ENSO in the western North Pacific in the high-resolution GFDL HiFLOR coupled climate model. J. Climate, 29, 1391-1415, https://doi.org/10.1175/ JCLI-D-15-0475.1.

_, G. A. Vecchi, G. Villarini, H. Murakami, A. Rosati, X. Yang, L. Jia, and F. Zeng, 2017: Modulation of western North Pacific tropical cyclone activity by the Atlantic meridional mode. Climate Dyn., 48, 631-647, https://doi.org/10.1007/ s00382-016-3099-2.

Zhao, H., 2016: A downscaling technique to simulate changes in western North Pacific tropical cyclone activity between two types of El Niño events. Theor. Appl. Climatol., 123, 487-501, https://doi.org/10.1007/s00704-015-1374-5.

_ L. Wu, and W. Zhou, 2010: Assessing the influence of the ENSO on tropical cyclone prevailing tracks in the western North Pacific. Adv. Atmos. Sci., 27, 1361-1371, https://doi.org/ 10.1007/s00376-010-9161-9.

Zhou, B. T., and X. Cui, 2014: Interdecadal change of the linkage between the North Atlantic Oscillation and the tropical cyclone frequency over the western North Pacific. Sci. China Earth Sci., 57, 2148-2155, https://doi.org/10.1007/ s11430-014-4862-z. 